\title{
Terceiro Setor: Aspectos relacionados à elaboração das demonstrações contábeis das fundações privadas mantenedoras de universidades do Estado de Santa Catarina
}

\begin{abstract}
José Alonso Borba
Doutorado em Controladoria e Contabilidade pela Universidade de São Paulo - USP

Universidade Federal de Santa Catarina - UFSC

E-mail: jalonso@cse.ufsc.br
\end{abstract}

Rogéria Pereira Bacharelado em Ciências Contábeis pela Universidade Federal de Santa Catarina - UFSC Universidade Federal de Santa Catarina - UFSC

E-mail: rogeriapr@hotmail.com

Eleonora Milano Falcão Vieira Doutorado em Engenharia de Produção pela Universidade Federal de Santa Catarina UFSC

E-mail: eleonorafalcao@gmail.com

\section{RESUMO}

Este estudo teve como objetivo verificar se as fundações privadas mantenedoras de universidades do Estado de Santa Catarina estão elaborando suas demonstrações contábeis de acordo com as normas editadas pelo Conselho Federal de Contabilidade aplicáveis as Entidades sem Fins Lucrativos (também conhecidas como Terceiro Setor), e se estão publicadas em seus sites na internet. De uma amostra inicial de dez fundações, amostra essa determinada pelo maior valor total dos ativos em 31 de dezembro de 2004, quatro fundações tiveram suas demonstrações contábeis analisadas. É verificada também a disponibilidade dessas demonstrações nos seus sites na internet. Relativamente às informações contidas em notas explicativas, observou-se que, das onze informações obrigatórias, oito não constavam em quase todas as fundações analisadas. São informações consideradas relevantes para esse tipo de entidade, pois dizem respeito diretamente à sociedade que está cada vez mais se utilizando dos demonstrativos contábeis para decidir para qual entidade fará sua doação. Ao término deste estudo concluiu-se que as fundações mencionadas não cumprem todas as determinações das normas, e que mais da metade das fundações da amostra inicial não disponibilizou em seus sites suas demonstrações contábeis.

Palavras Chaves: Terceiro Setor. Entidade sem fins lucrativos. Demonstrações Contábeis.

Third Sector: Aspects Related to Drawing Up Financial Statements of Private Foundations for the Maintenance of Universities in the State of Santa Catarina 
Terceiro Setor: Aspectos relacionados à elaboração das demonstrações contábeis das fundações privadas mantenedoras de universidades do Estado de Santa Catarina José Alonso Borba, Rogéria Pereira, Eleonora Milano Falcão Vieira

\section{ABSTRACT}

The objective of this study was to verify if the private foundations set up to maintain universities in the State of Santa Catarina are drawing up their financial statements according to the standards issued by the Federal Accountancy Council (Federal Accountancy Council) as applicable to Non-profit Entities (also known as the Third Sector), and if these have been published on their internet sites. From an initial sampling of ten foundations, a sampling determined by the highest value of assets on December 31,2004 , the financial statements of four foundations were examined. The availability of such financial statements on the Internet was also monitored. Concerning the information contained in explanatory notes, it was ascertained that almost all the foundations that were analyzed did not include eight of eleven mandatory notes. These data are considered relevant for this type of entity, since it has direct bearing on a society that is progressively depending more on financial statements to decide which entities will receive donations. On finalizing this study it was concluded that the aforementioned foundations do not comply with all the standards that have been established, and that over half the foundations in the initial sampling did not show their financial statements on their sites.

Key Words: Third Sector. Non-profit entities. Financial Statements.

\section{INTRODUÇÃO}

No Brasil, apesar de o Estado assumir cada vez mais um papel participativo na sociedade no que se refere à prestação de serviços públicos, sua ineficiência abre espaço para novas iniciativas, tendo a sociedade civil o objetivo de ajudar o Estado a cumprir seu papel de promotor do bem-estar social, surgindo então as chamadas Entidades do Terceiro Setor.

Entre as diversas organizações que fazem parte deste setor estão as fundações, que podem ser de direito público ou privado, e se constituem através de um patrimônio inicial doado para um fim social específico e definido pelo doador do patrimônio, não podendo este fim ser alterado pelos instituidores.

A contabilidade, que tem como uma das suas finalidades o registro das variações patrimoniais ocorridas em uma entidade ao longo de tempo e a geração de informações para tomadas e decisões, desempenha um papel importante na administração dessas entidades (Esben e Laffin, 2004), considerando as diversas fiscalizações e prestação de 
Terceiro Setor: Aspectos relacionados à elaboração das demonstrações contábeis das fundações privadas mantenedoras de universidades do Estado de Santa Catarina José Alonso Borba, Rogéria Pereira, Eleonora Milano Falcão Vieira

contas a que essas entidades estão sujeitas.

Por sua vez, o Conselho Federal de Contabilidade, órgão legalmente incumbido de normatizar as práticas contábeis no Brasil, estabeleceu critérios através de suas normas para disciplinar os aspectos contábeis das entidades do terceiro setor, critérios estes que vão desde a escrituração até a forma e estrutura das demonstrações contábeis.

Apesar da diversidade de artigos publicados, artigos disponíveis apenas na internet, porém não publicados, monografias, dissertações de mestrado e teses de doutorado relacionadas às entidades sem fins lucrativos, nenhuma pesquisa que tratasse da análise das demonstrações contábeis de fundações foi encontrada no período de pesquisa para a realização deste estudo.

Assim, este estudo procurou verificar se as fundações privadas mantenedoras de universidades do Estado de Santa Catarina estão elaborando suas demonstrações contábeis de acordo com as normas editadas pelo Conselho Federal de Contabilidade aplicáveis as entidades sem fins lucrativos, e as publicando em seus sites na internet, e a partir disto identificar possíveis distorções nas referidas demonstrações.

\section{REVISÃO BIBLIOGRÁFICA}

No Brasil, as entidades de interesse social têm origens de longas datas, se fortalecendo ao final do regime militar através de movimentos sociais e atitudes voluntárias formadas por pessoas religiosas e reconhecidas pela Igreja que realizavam um importante papel filantrópico e de assistência social. Ofereciam serviços como assistência médica e financeira, organizavam funerais e ofereciam refúgio para mendigos (Paes, 2003 p. 44).

Essas atitudes permanecem até hoje na sociedade, só que as ações sendo tomadas de uma forma cada vez mais organizada, e essa organização de pessoas para um único fim (geralmente $o$ atendimento as questões sociais) é o que vem se apresentando como Organizações do Terceiro Setor. 
Terceiro Setor: Aspectos relacionados à elaboração das demonstrações contábeis das fundações privadas mantenedoras de universidades do Estado de Santa Catarina José Alonso Borba, Rogéria Pereira, Eleonora Milano Falcão Vieira

\subsection{Conceituação do terceiro Setor}

$\mathrm{Na}$ atual sociedade brasileira percebe-se claramente uma divisão na economia, na qual encontram-se entidades definidas como sendo do Primeiro, Segundo e Terceiro Setor. De acordo com Esben e Laffin (2004, p. 13), "classifica-se por primeiro setor o Estado, cuja finalidade primeira é promover o atendimento às demandas públicas, como saúde, educação e segurança". São mantidas com os tributos que o próprio Estado impõe a sociedade.

Já o segundo setor, conforme abordado por Resende (2005, p. 01) "é compreendido como as organizações do mercado: pessoas físicas ou jurídicas de direito privado, encarregadas da produção e comercialização de bens e serviços, tendo como escopo o lucro e o enriquecimento do empreendedor". Este setor sobrevive basicamente em razão dos lucros que o capital produz.

Existe ainda um terceiro setor presente nas relações entre empresas e pessoas com a valorização social que, segundo Paes (2003, p.88), "ocupa uma posição intermediária que lhes permita prestar serviços de interesse social sem as limitações do estado, nem sempre evitáveis, e as ambições do mercado, muitas vezes inaceitáveis". Por sua vez, sobrevivem da prestação de serviços sociais ou ainda do recebimento de doações de particulares, subvenções públicas através de convênios, dentre outras. São também conhecidas como "Entidades sem Fins Lucrativos" ou ainda "Entidades de fins Não Econômicos".

As entidades que integram o terceiro setor originam-se a partir de movimentos sociais $\mathrm{e}$ que, de acordo com Souza (2005, p. 02) "transformaram-se em importantes instrumentos para a consecução de uma nova dinâmica social e democrática, em que as relações são orientadas pelos laços de solidariedade entre indivíduos, espírito voluntário, consenso e anseio do bem comum".

Como exemplos de entidades que fazem parte do terceiro setor, têm-se as sociedades civis sem fins lucrativos, Organizações Não-Governamentais - ONG's, associações, fundações, institutos, entidades de classe, sindicatos, dentre outros.

As entidades que compõem este setor atuam em diversas áreas do campo social, 
tais como: cultura e recreação, educação e pesquisa, saúde, assistência social, ambientalismo, desenvolvimento e habitação, defesa de direitos e atuação política, intermediários filantrópicos e promoção do voluntariado, atividades internacionais, religião, sindicatos e associações profissionais de empregadores, de empregados e de autônomos, dentre outros.

Em cada uma dessas áreas de atuação existem particularidades e obrigações diferenciadas que devem ser cumpridas, como é o caso das entidades que atuam na área de Educação e Pesquisa, objeto deste estudo.

\subsection{Fundações}

As fundações são entidades reconhecidas no Código Civil Brasileiro, em seu artigo 44, sendo entidades criadas a partir de um patrimônio destacado daquele de seu (s) fundador (res) que passam a ser de interesse social, sendo sua administração e manutenção de atividades quanto a sua finalidade de interesse público.

São classificadas de acordo com sua forma de instituição em fundações de direito privado e fundações instituídas pelo poder público. Na classificação das fundações privadas estão as fundações de apoio às instituições de ensino superior, que são criadas com a finalidade de dar apoio a projetos de pesquisa, ensino e extensão e de desenvolvimento institucional, científico e tecnológico as instituições de ensino superior, sejam elas federais ou particulares. São criadas mediante a aprovação dos atos de instituição e do respectivo estatuto pelo Ministério Público.

Este tipo de fundação, conforme defende Paes (2003, p. 175),

são fundações de direito privado que foram instituídas por pessoas físicas (professores universitários, por exemplo) ou pessoas jurídicas (que podem ser as próprias universidades ou instituições de ensino superior), visando auxiliar e fomentar os projetos de pesquisa, ensino e extensão das universidades federais e demais instituições de ensino superior, públicas ou privadas.

Reconhecendo o trabalho dessas entidades, o Poder Público tem concedido benefícios fiscais de ordem tributária (imunidades e isenções) para incentivar a criação 
Terceiro Setor: Aspectos relacionados à elaboração das demonstrações contábeis das fundações privadas mantenedoras de universidades do Estado de Santa Catarina José Alonso Borba, Rogéria Pereira, Eleonora Milano Falcão Vieira

dessas entidades ou ainda a sobrevivência das mesmas, uma vez que as atividades por elas desenvolvidas fazem parte das obrigações do Estado.

\subsection{Aspectos Contábeis}

De acordo com Esben e Laffin (2004, p. 18):

pode-se afirmar que na existência de uma entidade, independente de sua classificação e de seus objetivos, a contabilidade se faz presente, registrando e acompanhando as alterações no patrimônio ao longo do tempo, gerando informações úteis à tomada de decisão e à sua continuidade.

Embora os aspectos legais de constituição e funcionamento das organizações que fazem parte do terceiro setor se diferenciem em determinados pontos daquelas referentes às empresas do segundo setor (comerciais, industriais, prestadoras de serviços, financeiras, etc.), não há legislação contábil específica e definida como sendo para aquele tipo de entidade, como existe a Lei das Sociedades por Ações (no 6.404/76). Devido a isto, é com frequência que se encontram demonstrações contábeis publicadas de acordo com a referida lei, mesmo se tratando de entidades do terceiro setor.

Por sua vez, o Conselho Federal de Contabilidade estabeleceu critérios que devem ser aplicados às entidades sem fins lucrativos, também denominadas entidades de fins não econômicos, desmembradas da Norma Brasileira de Contabilidade ํo 10 NBC T 10 - Dos Aspectos Contábeis Específicos em Entidades Diversas, a saber:

- NBC T 10.4 - FUNDAÇÕES (aprovada pela Resolução CFC n`837/1999);

- NBCT 10.16 - ENTIDADES QUE RECEBEM DOAÇÕES, SUBVENÇÕES, CONTRIBUIÇÕES, AUXÍLIOS E DOAÇÕES (revogada pela NBC T 19.4, aprovada pela Resolução $n^{\circ} 1.026 / 2005$ do CFC);

- NBC T 10.18 - ENTIDADES SINDICAIS E ASSOCIAÇÕES DE CLASSE (aprovada pela Resolução CFC n`838/1999);

- NBC T 10.19 - ENTIDADES SEM FINALIDADE DE LUCROS (aprovada pela 
Terceiro Setor: Aspectos relacionados à elaboração das demonstrações contábeis das fundações privadas mantenedoras de universidades do Estado de Santa Catarina José Alonso Borba, Rogéria Pereira, Eleonora Milano Falcão Vieira

Resolução CFC n 877/2000, alterada pela Resolução n 926/2001 e pela Resolução $\left.n^{\circ} 966 / 2003\right)$.

O quadro a seguir resume as principais alterações que as entidades sem fins lucrativos devem considerar quando elaboram suas demonstrações contábeis, e em seguida são apresentadas considerações relativas a ele.

\begin{tabular}{|c|c|}
\hline “Entidades Diversas” & Entidades Sem Fins Lucrativos \\
\hline Capital Social & Patrimônio Social (item 3.2 da NBC T 10.19) \\
\hline Lucros ou Prejuízos Acumulados & $\begin{array}{c}\text { Superávits ou Déficits Acumulados (item 3.2 } \\
\text { da NBC T 10.19) }\end{array}$ \\
\hline Demonstração do Resultado do Exercício & $\begin{array}{c}\text { Demonstração do Superávit ou Déficit (item } \\
5.1 \text { da NBC T 10.4) }\end{array}$ \\
\hline Demonstração das Mutações do Patrimônio \\
Líquido & $\begin{array}{c}\text { Demonstração das Mutações do Patrimônio } \\
\text { Social (item 6.1 da NBC T 10.4) }\end{array}$ \\
\hline
\end{tabular}

Quadro 1: Diferenças quanto às nomenclaturas para as Entidades sem fins lucrativos Fonte: elaborado pela autora

Os itens de avaliação dos componentes patrimoniais, de registros contábeis, de demonstrações contábeis, de divulgação das mesmas e das notas explicativas obedecem a uma mesma prescrição legal: devem ser elaboradas com base nas determinações da NBC T 3 - Conceito, Conteúdo, Estrutura e Nomenclatura das Demonstrações Contábeis, e sua divulgação deverá observar as disposições da NBC T 6 - Da Divulgação das Demonstrações Contábeis. Diferem entre si basicamente no que se refere à caracterização das atividades e às situações especiais inerentes a cada atividade.

Segundo a NBC T 10.4, item 6.2 "as Fundações estão dispensadas da elaboração da Demonstração de Lucros ou Prejuízos Acumulados, por estar incluída na Demonstração das Mutações do Patrimônio Social".

A NBC T 6 - Da Divulgação das Demonstrações Contábeis define que as demonstrações contábeis devem ser publicadas com o "objetivo de fornecer, aos seus usuários, um conjunto mínimo de informações de natureza patrimonial, 
econômica, financeira, legal, física e social que lhes possibilitem o conhecimento e a análise da situação da Entidade".

A NBC T 4 - Fundações, reforçada pela determinação da NBC T 10.19 - Entidades Sem Finalidade de Lucros, diz que as demonstrações contábeis devem ser complementadas por Notas Explicativas que contenham um mínimo de informações definidas nesta última norma, conforme abaixo:

a. o resumo das principais práticas contábeis;

b. os critérios de apuração das receitas e das despesas, especialmente com gratuidades, doações, subvenções, contribuições e aplicações de recursos;

c. as contribuições previdenciárias relacionadas com a atividade assistencial devem ser demonstradas como se a entidade não gozasse de isenção, conforme normas do Instituto Nacional do Seguro Social (INSS);

d. as subvenções recebidas pela entidade, a aplicação dos recursos e as responsabilidades decorrentes dessas subvenções;

e. os fundos de aplicação restrita e responsabilidades decorrentes desses fundos;

f. evidenciação dos recursos sujeitos a restrições ou vinculações por parte do doador;

g. eventos subsequentes à data do encerramento do exercício que tenham, ou possam vir a ter efeito relevante sobre a situação financeira e os resultados futuros da entidade;

h. as taxas de juros, as datas de vencimento e as garantias das obrigações a longo prazo;

i. informações sobre os tipos de seguro contratados;

j. as entidades educacionais, além das notas explicativas, devem evidenciar a adequação das receitas com as despesas de pessoal, segundo parâmetros estabelecidos pela Lei das Diretrizes e Bases da Educação e sua regulamentação;

k. as entidades beneficiadas com isenção de tributos e contribuições devem evidenciar suas receitas com e sem gratuidade de forma segregada, e os benefícios fiscais gozados.

De modo geral, percebe-se que as demonstrações contábeis das entidades sem 
Terceiro Setor: Aspectos relacionados à elaboração das demonstrações contábeis das fundações privadas mantenedoras de universidades do Estado de Santa Catarina José Alonso Borba, Rogéria Pereira, Eleonora Milano Falcão Vieira

fins lucrativos devem seguir a mesma padronização das demais entidades, exceto quanto a alguns aspectos de capital social e lucro ou prejuízo, e ainda relativamente à alguns registros contábeis, principalmente no que diz respeito ao recebimento dos diversos recursos que essas entidades podem ter acesso.

\subsection{Pesquisas e Estudos Anteriores}

Apesar de se encontrar alguns livros e artigos sobre o tema Terceiro Setor, poucas pesquisas empíricas direcionadas as demonstrações contábeis neste setor foram encontradas, embora os outros diversos temas que versam sobre esse tipo de entidade tenham sido abordadas por alguns autores, como os exemplos a seguir apresentados:

Quanto ao aspecto contábil, Esben e Laffin (2004) apresentaram em sua pesquisa alguns procedimentos contábeis realizados em uma entidade do terceiro setor, através de um estudo de caso em uma associação. Neste estudo, foi enfatizada a importância da contabilidade para as entidades do terceiro setor, com o propósito de, segundo os autores (2004, p. 18) facilitar a "comunicação entre a entidade e os usuários não apenas das informações contábeis, mas também daqueles que se beneficiam das atividades da entidade, assim como sua relação com a sociedade em geral".

Ainda na área contábil, Macedo (2005) apresenta de maneira geral em seu artigo os princípios e convenções contábeis, descreve a NBC T 10.4 - Fundações, destacando seus principais tópicos e determinações, assim como descreve a NBC T 10.19 Entidades sem Finalidades de Lucro. A partir daí o autor encontra deficiências relacionadas a conflitos de ideias entre leis, decretos, medidas provisórias, resoluções e portarias editadas pelo estado, os quais apresentam para casos específicos inúmeros procedimentos com regulamentações diferentes.

Destaca em seu estudo que à falta de padronização quanto à prestação de contas das entidades do terceiro setor. O autor afirma que "não existe um modelo único para o plano de contas, tampouco não há preocupação em se trabalhar com base em centros de custos", embora cada plano de contas deva ser adaptado às peculiaridades das operações e necessidades internas das entidades. 
Terceiro Setor: Aspectos relacionados à elaboração das demonstrações contábeis das fundações privadas mantenedoras de universidades do Estado de Santa Catarina José Alonso Borba, Rogéria Pereira, Eleonora Milano Falcão Vieira

\section{METODOLOGIA DO ENSINO}

Quanto aos objetivos, neste estudo foi utilizado o método descritivo, pois os dados observados foram descritos de forma a relatar, identificar e apresentar os resultados obtidos. Trata-se ainda de uma pesquisa bibliográfica, considerando que toda a revisão do tema proposto foi realizada através da coleta de material já elaborado.

Este estudo pode ser também classificado como documental, pois as demonstrações contábeis analisadas estão em sua forma primária e serão apresentados aqui de forma secundária, como quadros e relatórios. Quanto à abordagem do problema, trata-se de uma pesquisa qualitativa pelo fato de os dados pesquisados serem analisados com certa profundidade, e não se utilizar instrumentos estatísticos, tanto na coleta quanto no tratamento dos dados.

A amostra das fundações a serem analisadas aqui foi selecionada através de relação fornecida pelo Ministério Público do Estado de Santa Catarina, na qual estavam apresentadas, por ordem decrescente do total de seus ativos em 31 de dezembro de 2004, todas as fundações que prestam contas ao Estado.

A partir daí foram extraídas as fundações que atuam na área de Educação e Pesquisa. Estabeleceu-se então uma amostra inicial com dez fundações privadas mantenedoras de Universidades do Estado de Santa Catarina para este estudo, conforme apresentado no Quadro 3. $O$ ano a ser analisado foi o de 2004, mesmo ano utilizado como base para a classificação do valor total dos ativos. 
Terceiro Setor: Aspectos relacionados à elaboração das demonstrações contábeis das fundações privadas mantenedoras de universidades do Estado de Santa Catarina José Alonso Borba, Rogéria Pereira, Eleonora Milano Falcão Vieira

\begin{tabular}{|c|c|c|}
\hline & Nome & $\begin{array}{c}\text { Total Ativo em } \\
\mathbf{3 1 . 1 2 . 2 0 0 4}\end{array}$ \\
\hline 1 & Fundação Universidade do Vale do Itajaí - UNIVALI & $\mathrm{R} \$ 194.742 .985,00$ \\
\hline 2 & Fundação Universidade do Sul de Santa Catarina - UNISUL & $\mathrm{R} \$ 117.802 .706,03$ \\
\hline 3 & Fundação Educacional da Região de Joinville - UNIVILLE & $\mathrm{R} \$ 69.738 .493,00$ \\
\hline 4 & Fundação Universidade do Oeste de Santa Catarina - FUNOESC & $\mathrm{R} \$ 68.475 .026,01$ \\
\hline 5 & Fundação das Escolas Unidas do Planalto Catarinense - UNIPLAC & $\mathrm{R} \$ 33.579 .339,69$ \\
\hline 6 & $\begin{array}{c}\text { Fundação Universitária do Desenvolvimento do Oeste - FUNDESTE - } \\
\text { UNOCHAPECÓ }\end{array}$ & $\mathrm{R} \$ 19.985 .414,24$ \\
\hline 7 & Fundação Universidade do Contestado Concórdia & $\mathrm{R} \$ 18.437 .912,47$ \\
\hline 8 & Fundação Educacional Regional Jaraguaense - FERJ & $\mathrm{R} \$ 18.057 .895,90$ \\
\hline 9 & $\begin{array}{c}\text { Fundação Universidade para o Desenvolvimento do Alto Vale do Itajaí - } \\
\text { UNIDAVI }\end{array}$ & $\mathrm{R} \$ 16.229 .554,68$ \\
\hline 10 & Fundação Universidade do Contestado - Campus Universitário de & $\mathrm{R} \$ 14.782 .939,66$ \\
\hline
\end{tabular}

Quadro 2: Amostra inicial das fundações.

Fonte: elaborado pela autora

Para obtenção das demonstrações contábeis, foram realizadas pesquisas nos sites das fundações na internet (fundações da amostra inicial), sendo que apenas três as disponibilizaram em seus sites. Foram encaminhados ainda uma média de quatro e-mails para cada fundação, além de contato telefônico, durante o período compreendido entre outubro de 2005 e abril de 2006, sendo que apenas uma informou que as publicara num jornal de grande circulação.

As demais fundações não se manifestaram até o término desta pesquisa, embora houvesse tido contato telefônico. Finalmente, chegou-se a amostra das quatro fundações que efetivamente tiveram suas demonstrações contábeis analisadas (conforme descritas abaixo) e, portanto, a análise dos resultados apresentada aqui se refere a essas quatro fundações.

- Fundação Universidade do Sul de Santa Catarina - UNISUL

- Fundação Educacional da Região de Joinville - UNIVILLE 
Terceiro Setor: Aspectos relacionados à elaboração das demonstrações contábeis das fundações privadas mantenedoras de universidades do Estado de Santa Catarina José Alonso Borba, Rogéria Pereira, Eleonora Milano Falcão Vieira

- Fundação das Escolas Unidas do Planalto Catarinense - UNIPLAC

- Fundação Universidade para o Desenvolvimento do Alto Vale do Itajaí - UNIDAVI

Após definida a amostra final, foi investigada se todas as entidades apresentaram as demonstrações contábeis exigidas pela NBC T 10.3, bem como se as contas Patrimônio Líquido e Lucros ou Prejuízos Acumulados foram substituídas pelas contas Patrimônio Social e Superávits ou Déficits Acumulado, respectivamente, de acordo com o que determina a NBC T 10.19 .

Foi investigado ainda se a Demonstração do Resultado do Exercício e a Demonstração das Mutações do Patrimônio Social tiveram suas denominações alteradas para Demonstração do Superávit ou Déficit do Exercício e Demonstração das Mutações do Patrimônio Social, respectivamente, ambas de acordo com a NBC T 10.4.

Através da análise da Demonstração das Mutações do Patrimônio Social, foi verificado se o valor do Superávit ou Déficit de exercícios anteriores foi transferido para a conta Patrimônio Social, conforme determinação da NBC T 10.19. Por último, foi verificado se todas as fundações apresentaram notas explicativas, e se estas apresentaram o mínimo de informações exigidas pela NBC T 10.19.

\section{ANÁLISE DOS RESULTADOS}

Em pesquisa ao site das dez fundações na internet, observou-se certa dificuldade quanto à obtenção das demonstrações contábeis, considerando que de dez fundações da amostra inicial, apenas três disponibilizaram suas demonstrações contábeis no site, e uma foi obtida após contato por correio eletrônico. Importante ressaltar que todas as fundações disponibilizaram seus estatutos, e algumas delas apresentaram informações sociais como Balanço Social, e também informações relacionadas às suas normas e regulamentos internos.

\subsection{Quanto aos itens investigados nas demonstrações contábeis}

O Quadro 3 traz os itens que foram investigados nas demonstrações contábeis das 
Terceiro Setor: Aspectos relacionados à elaboração das demonstrações contábeis das fundações privadas mantenedoras de universidades do Estado de Santa Catarina José Alonso Borba, Rogéria Pereira, Eleonora Milano Falcão Vieira

fundações, bem como o resultado da pesquisa.

\begin{tabular}{|c|c|c|c|c|c|}
\cline { 3 - 5 } \multicolumn{2}{|c|}{ Questão } & \multicolumn{2}{c|}{ Fundações } \\
\hline 1 & $\begin{array}{c}\text { Apresenta todas as demonstrações que determina } \\
\text { a NBC T 3? }\end{array}$ & Sim & Sim & Sim & Sim \\
\hline 2 & $\begin{array}{c}\text { A conta Patrimônio Líquido foi substituída } \\
\text { por Patrimônio Social, conforme NBC } \\
\text { T10.19? }\end{array}$ & Sim & Sim & Sim & Não \\
\hline 3 & $\begin{array}{c}\text { A conta Lucros/Prejuízos Acumulados foi } \\
\text { substituída por Superávits/Déficits Acumulados, } \\
\text { conforme NBC T 10.19? }\end{array}$ & Sim & Sim & Sim & Sim \\
\hline 4 & $\begin{array}{c}\text { A Demonstração do Resultado do Exercício } \\
\text { teve sua denominação alterada para } \\
\text { Demonstração do Superávit ou Déficit do } \\
\text { Exercício, conforme NBC T 10.4? }\end{array}$ & Sim & Sim & Sim & Não \\
\hline 5 & $\begin{array}{c}\text { A Demonstração das Mutações do Patrimônio } \\
\text { Líquido teve sua denominação alterada para } \\
\text { Demonstração das Mutações do Patrimônio } \\
\text { Social, conforme NBC T 10.4? }\end{array}$ & Sim & Sim & Sim & Não \\
\hline 6 & $\begin{array}{c}\text { O valor do Superávit ou Déficit de exercícios } \\
\text { anteriores foi transferido para a conta } \\
\text { Patrimônio Social, conforme NBC T 10.19? }\end{array}$ & Não & Sim & Não & Sim \\
\hline 7 & \begin{tabular}{c} 
Apresenta Notas Explicativas? \\
\hline
\end{tabular} & Sim & Sim & Sim & Sim \\
\hline
\end{tabular}

Quadro 3: Questões investigadas nas Demonstrações Contábeis das Fundações. Fonte: elaborado pela autora

\section{Item 1:}

Verificou-se que todas as entidades observaram as determinações da norma, ou seja, todas apresentaram as demonstrações contábeis exigidas pela norma, inclusive as Notas Explicativas. Algumas delas (UNIDAVI, UNISUL e UNIVILLE) apresentaram demonstrações adicionais não obrigatórias, como a Demonstração do Fluxo de Caixa, Movimentação do Ativo Permanente e Demonstração do Valor Adicionado, elaboradas de acordo com a necessidade de cada entidade.

Pode-se constatar que as quatro entidades investigadas foram devidamente auditadas, pois disponibilizaram em seus sites Parecer dos Auditores Independentes e, 
Terceiro Setor: Aspectos relacionados à elaboração das demonstrações contábeis das fundações privadas mantenedoras de universidades do Estado de Santa Catarina José Alonso Borba, Rogéria Pereira, Eleonora Milano Falcão Vieira

além disso, apresentaram Parecer do Conselho de Administração ou Conselho Curador, demonstrando preocupação em informar que as demonstrações contábeis publicadas foram aprovadas pelos órgãos fiscalizadores internos da entidade.

\section{Item 2:}

Quanto à substituição da nomenclatura Patrimônio Líquido por Patrimônio Social, segundo item investigado, apenas a Fundação UNIDAVI não fez a devida substituição da conta título, embora apresentasse uma conta analítica com essa nomenclatura. Considera-se que essa fundação não observou a determinação da norma por ainda apresentar a conta Patrimônio Líquido, independente de conta título ou analítica, pois a norma não fala dessa classificação.

Por sua vez, a fundação UNISUL menciona em notas explicativas que "o Patrimônio Líquido Social da fundação é composto pelo resultado do Patrimônio Institucional, somado da reserva de doações de bens, reserva de reavaliação e o superávit/déficit”. Destaca-se aqui a existência da conta Patrimônio Líquido Social, sem previsão em norma.

\section{Item 3:}

Neste item que trata da substituição da conta Lucros ou Prejuízos Acumulados para Superávits ou Déficits Acumulados, verificou-se que as quatro entidades investigadas fizeram essa alteração. Embora nada tenha sido encontrado em nenhuma norma a respeito da existência de uma conta chamada Superávit Acumulado, as Fundações

UNIPLAC e UNISUL apresentaram-na em seus balanços patrimoniais. Outra conta sem existência prevista em norma é a Patrimônio Institucional, encontrada no Balanço Patrimonial da Fundação UNISUL.

\section{Item 4:}

A Fundação UNIDAVI foi a única que não alterou a nomenclatura da 
Terceiro Setor: Aspectos relacionados à elaboração das demonstrações contábeis das fundações privadas mantenedoras de universidades do Estado de Santa Catarina José Alonso Borba, Rogéria Pereira, Eleonora Milano Falcão Vieira

Demonstração do Resultado do Exercício para Demonstração do Superávit ou Déficit do Exercício, apesar de seu resultado ter tido a nomenclatura substituída por Superávit (Déficit).

\section{Item 5:}

Novamente a Fundação UNIDAVI não fez a devida alteração na nomenclatura da Demonstração das Mutações do Patrimônio Líquido para Demonstração das Mutações do Patrimônio Social. Entende-se que, uma vez que as fundações não apresentam Patrimônio Líquido, não podem ter demonstração que descriminam suas mutações.

\section{Item 6:}

Em análise às Demonstrações das Mutações do Patrimônio Social para verificação da transferência resultado do período para esta última conta, verificou-se que as fundações UNISUL e UNIPLAC não transferiram o valor do déficit do exercício para a conta Patrimônio Social, mas sim para a conta superávits ou déficits acumulados. Como já mencionado anteriormente, não foi encontrada previsão legal que justifique a existência desta última conta. Observou-se ainda que uma delas apresenta a conta Patrimônio Social como uma conta título, sendo as contas Patrimônio Institucional, Reservas e Resultado Acumulado, contas analíticas desse grupo.

\section{Item 7:}

Verificou-se que todas as quatro fundações elaboraram notas explicativas às demonstrações contábeis. O tópico 4.2 deste capítulo traz a análise quanto as informações contidas nessas notas.

\subsection{Quanto às informações contidas em notas explicativas}

O Quadro 4 demonstra quais informações devem conter nas notas explicativas, de acordo com a NBC T 10.19, e em seguida é apresentado o resultado da análise em forma de relatório. 
Terceiro Setor: Aspectos relacionados à elaboração das demonstrações contábeis das fundações privadas mantenedoras de universidades do Estado de Santa Catarina

José Alonso Borba, Rogéria Pereira, Eleonora Milano Falcão Vieira

\begin{tabular}{|c|c|c|c|c|c|}
\hline \multirow[b]{2}{*}{ Item } & \multirow[b]{2}{*}{ Descrição } & \multicolumn{3}{|c|}{ Fundações } & \multirow[b]{2}{*}{ UNIDAVI } \\
\hline & & UNISUL & UNIVILLE & UNIPLAC & \\
\hline$A$ & O resumo das principais práticas contábeis; & Sim & Sim & Sim & Sim \\
\hline B & $\begin{array}{c}\text { Os critérios de apuração das receitas e das } \\
\text { despesas, especialmente com gratuidades, } \\
\text { doações, subvenções, contribuições e } \\
\text { aplicações de recursos; }\end{array}$ & Sim & Sim & $\operatorname{Sim}$ & Não \\
\hline $\mathrm{C}$ & \begin{tabular}{|c|} 
As contribuições previdenciárias \\
relacionadas com a atividade assistencial \\
devem ser demonstradas como se a \\
entidade não gozasse de isenção, \\
conforme normas do Instituto Nacional do \\
Seguro Social (INSS); \\
\end{tabular} & Sim & Sim & Não & Sim \\
\hline $\mathrm{D}$ & $\begin{array}{c}\text { As subvenções recebidas pela entidade, a } \\
\text { aplicação dos recursos e as } \\
\text { responsabilidades decorrentes dessas } \\
\text { subvenções; }\end{array}$ & Não & Não & Não & Não \\
\hline$E$ & $\begin{array}{l}\text { Os fundos de aplicação restrita e } \\
\text { responsabilidades decorrentes desses } \\
\text { fundos; }\end{array}$ & Não & Não & Não & Não \\
\hline $\mathrm{F}$ & $\begin{array}{l}\text { Evidenciação dos recursos sujeitos a } \\
\text { restrições ou vinculações por parte do } \\
\text { doador; }\end{array}$ & Não & Não & Não & Não \\
\hline $\mathrm{G}$ & $\begin{array}{c}\text { Eventos subseqüentes à data do } \\
\text { encerramento do exercício que tenham, ou } \\
\text { possam vir a ter efeito relevante sobre a } \\
\text { situação financeira e os resultados futuros } \\
\text { da entidade; }\end{array}$ & Não & Não & Não & Sim \\
\hline $\mathrm{H}$ & $\begin{array}{c}\text { As taxas de juros, as datas de vencimento } \\
\text { e as garantias das obrigações a longo } \\
\text { prazo; }\end{array}$ & Não & Não & Não & Sim \\
\hline I & $\begin{array}{l}\text { Informações sobre os tipos de seguro } \\
\text { contratados; }\end{array}$ & Sim & Sim & Sim & Sim \\
\hline $\mathrm{J}$ & \begin{tabular}{|} 
As entidades educacionais, além das notas \\
explicativas, devem evidenciar a \\
adequação das receitas com as despesas \\
de pessoal, segundo parâmetros \\
estabelecidos pela Lei das Diretrizes e \\
Bases da Educação e sua regulamentação;
\end{tabular} & Não & Não & Não & Não \\
\hline $\mathrm{K}$ & $\begin{array}{c}\text { As entidades beneficiadas com isenção de } \\
\text { tributos e contribuições devem evidenciar } \\
\text { suas receitas com e sem gratuidade de } \\
\text { forma segregada, e os benefícios fiscais } \\
\text { gozados. }\end{array}$ & Sim & Não & Não & Sim \\
\hline
\end{tabular}

Quadro 4: Informações obrigatórias pela NBC T 10.19

Fonte: elaborado pela autora 
Terceiro Setor: Aspectos relacionados à elaboração das demonstrações contábeis das fundações privadas mantenedoras de universidades do Estado de Santa Catarina

José Alonso Borba, Rogéria Pereira, Eleonora Milano Falcão Vieira

\section{Item A:}

Todas as entidades investigadas observaram a exigência da norma, ou seja, apresentaram as principais práticas contábeis adotadas pela entidade.

\section{Item B:}

Quanto aos critérios de apuração de receitas e despesas, apenas a Fundação UNIDAVI não apresentou tais critérios, nem ao menos o critério de apuração do resultado, diferentemente das outras três fundações investigadas que as demonstraram com clareza em suas notas explicativas. A Fundação UNIPLAC apresentou o critério de apuração de seu resultado, como segue:

As receitas, despesas, gratuidades, doações e subvenções, bem como gastos e despesas relacionadas com a atividade assistencial, foram contabilizadas separadamente, de acordo com a sua natureza e encontram-se demonstradas em quadros específicos das notas explicativas ou na demonstração do resultado.

Outras informações quanto a critérios de apuração que foram encontradas nas notas explicativas das quatro fundações investigadas referem-se a estoques e imobilizado.

\section{Item C:}

Apenas a Fundação UNIPLAC não demonstrou o montante obtido com isenções de contribuições previdenciárias - cota patronal. A Fundação UNISUL demonstrou em nota explicativa específica para essa informação: "Os custos da imunidade da quota patronal de previdência social usufruída pela entidade em 2004 e 2003 foram de [...] respectivamente", bem como a fundação UNIVILLE. Já a fundação UNIDAVI que apresentou o valor de sua isenção em nota que tratava do montante concedido pela fundação como gratuidades, além de apresentar o montante de isenção do PIS e da COFINS. 
Terceiro Setor: Aspectos relacionados à elaboração das demonstrações contábeis das fundações privadas mantenedoras de universidades do Estado de Santa Catarina José Alonso Borba, Rogéria Pereira, Eleonora Milano Falcão Vieira

Item D:

Nenhuma das quatro fundações analisadas demonstrou em suas notas explicativas a aplicação dos recursos provenientes de subvenções, nem as responsabilidades decorrentes desse recebimento, embora as Fundações UNIVILLE e UNISUL tenham demonstrado o valor total recebido como subvenção nos anos de $2004 \mathrm{e}$ 2005.

Observação importante foi que as Fundações UNIPLAC e UNIDAVI não mencionaram em momento algum em suas notas explicativas que receberam subvenções, nem apresentaram em suas Demonstração do Superávit ou Déficit.

\section{Item E:}

Este item, que trata dos fundos de aplicação restrita e responsabilidades, foi considerada de difícil entendimento para fins desta pesquisa, pois nenhuma fundação investigada mencionou em notas que suas aplicações mantidas em instituições financeiras tivesse algum tipo de restrição ou gerasse certa responsabilidade.

\section{Item F:}

Neste item que trata da evidenciação de recursos sujeitos a restrições ou vinculações por parte do doador, foi possível observar mais uma vez que nenhuma das entidades incluiu esta informação em notas explicativas, nem ao menos apresentou que obteve receitas com doações em suas Demonstrações do Superávit ou Déficit. Apesar disso, todas as fundações apresentaram receitas diversas, mas nenhuma delas esclareceu em nota explicativa a que essas receitas se referem.

\section{Item G:}

Observou-se que apenas a fundação UNIDAVI apresentou nota referente à conta de ajustes de exercícios anteriores. Nela estão demonstrados os valores reconhecidos, tanto de natureza devedora com credora, informando o saldo final. Contudo, não se sabe quais foram os eventos que efetivamente tiveram relevância no resultado da entidade, 
Terceiro Setor: Aspectos relacionados à elaboração das demonstrações contábeis das fundações privadas mantenedoras de universidades do Estado de Santa Catarina José Alonso Borba, Rogéria Pereira, Eleonora Milano Falcão Vieira

pois nesta pesquisa foi realizada análise superficial das demonstrações contábeis, e não análise mais próxima de auditoria.

\section{Item H:}

Quanto as obrigações a longo prazo, a única fundação que apresentou todas as informações exigidas pela norma foi a UNIDAVI, inclusive apresentou o número de parcelas a pagar em 31.12.2004, além de previsão de amortização e de encargos mensais.

Embora a fundação UNISUL tivesse demonstrado de forma clara as datas de vencimentos e as garantias relativas a cada empréstimo efetuado, ela não apresentou as taxas de juros, confirmado pelo trecho extraído de suas notas explicativas: "estão demonstrados pelos seus valores originais, acrescidos dos encargos financeiros previstos em cada contrato". Por sua vez, a fundação UNIVILLE apresentou somente os saldos das contas por banco financiador, e não apresentou mais nenhuma informação a respeito.

A fundação UNIPLAC apresentou em nota específica, informações como objetivo do financiamento, vencimento, taxas de juros, valor do contrato e saldo, não demonstrando quais garantias foram dadas para tais obrigações.

\section{Item I:}

Relativamente aos seguros contratados pelas entidades, todas as entidades observaram a esta determinação: a fundação UNIPLAC apresentou quadro com informações referente a objeto, cobertura e limite máximo de indenização; já a fundação UNIVILLE traz somente informações e não apresenta valores, apenas menciona as apólices são "consideradas pela Administração suficientes para cobrir eventuais sinistros", assim como a UNISUL, que informou que "mantém contratados seguros sobre seus bens móveis e imóveis"; e a fundação UNIDAVI traz ainda que "as coberturas de seguros obedece às orientações técnicas de especialistas e de conformidade com o grau de risco envolvido".

Já que a norma não determina quais informações efetivamente devem conter 
referente aos seguros, considera-se que todas as entidades seguiram a exigência da norma.

\section{Item J:}

Para analisar este item, foi realizada nova pesquisa ao site das fundações, com a finalidade de encontrar informações quanto a evidenciação das receitas com as despesas de pessoal, segundo parâmetros da Lei de Diretrizes e Bases da Educação, mas nada foi encontrado a respeito. Já que estas informações não devem constar em notas explicativas, não pode-se afirmar com exatidão que tal item não foi observado pelas entidades somente pelo fato de estas informações não estarem disponíveis em seus sites na internet, pois elas podem ter prestado contas ao Ministério da Educação, e somente não ter disponibilizado a qualquer usuário.

\section{Item K:}

Item que trata dos benefícios fiscais gozados pelas fundações verificou-se que duas fundações observaram esta determinação: a fundação UNIDAVI apresentou em nota específica chamada "Gratuidades" o valor dos benefícios fiscais gozados, bem como o valor das receitas, o percentual e valores das gratuidades; e a fundação UNISUL, embora tenha demonstrado na nota que trata do "Contexto Operacional" os benefícios fiscais gozados, mas não em valores monetários (apenas citou quais são eles): 
Terceiro Setor: Aspectos relacionados à elaboração das demonstrações contábeis das fundações privadas mantenedoras de universidades do Estado de Santa Catarina José Alonso Borba, Rogéria Pereira, Eleonora Milano Falcão Vieira A instituição goza dos benefícios fiscais descritos a seguir.

- Imunidade do Imposto de Renda Pessoa Jurídica e da Contribuição Social Sobre o Lucro, Imposto sobre Serviço de Qualquer Natureza, Imposto Predial, Territorial Urbano e Imposto sobre a Propriedade de Veículos Automotores.

- Imunidade da Contribuição para Financiamento da Seguridade Social - COFINS.

- Dispensa do repasse do Imposto de Renda Retido na Fonte - IRRF sobre proventos de qualquer natureza, a serem recolhidos pela Fundação, conforme Lei Municipal 1.727 de 23 de dezembro de 1992.

- Imunidade das contribuições ao Instituto Nacional do Seguro Social - INSS, em decorrência do Certificado de Entidade Beneficente de Assistência Social, fornecido pelo Conselho Nacional de Assistência Social -CNAS.

As fundações UNIVILLE e UNIPLAC não apresentaram em suas notas explicativas os benefícios fiscais gozados, apenas mostram os valores com gratuidades.

\section{CONSIDERAÇÕES FINAIS}

Para que os contabilistas realizem seu trabalho da forma mais correta possível, é preciso seguir algumas regras e legislações no que diz respeito à escrituração contábil e práticas contábeis adotadas. Para as entidades do terceiro setor isso não é diferente.

Concluiu-se com esta pesquisa que a elaboração das demonstrações está sendo realizada com base nas determinações das normas em questão. Quanto a publicação das mesmas nos sites das fundações, conclui-se que elas não são publicadas com frequência.

Em pesquisa feita aos sites das fundações relacionadas na amostra inicial, pôdese constatar certa falta de transparência quanto à divulgação das mesmas, considerando que apenas quatro fundações (das dez iniciais) puderam ser analisadas: três delas as disponibilizava em seus sites, e uma informou que as publicara em jornal de circulação regional.

Quanto a diferenciação de algumas terminologias nas demonstrações contábeis (foram sete, os itens aqui investigados) observou-se que quatro deles não foram 
Terceiro Setor: Aspectos relacionados à elaboração das demonstrações contábeis das fundações privadas mantenedoras de universidades do Estado de Santa Catarina José Alonso Borba, Rogéria Pereira, Eleonora Milano Falcão Vieira

cumpridos por pelo menos uma fundação, estando eles apresentados no item 4 deste estudo. A observação destes itens pode ser considerada básica para fins deste estudo, pois as normas são claras e não deixam dúvidas quando fazem essas determinações.

Relativamente às informações contidas em notas explicativas, observou-se que, das onze informações obrigatórias, oito não constavam em quase todas as fundações analisadas. São informações consideradas relevantes para esse tipo de entidade, pois dizem respeito diretamente à sociedade que está cada vez mais se utilizando dos demonstrativos contábeis para decidir para qual entidade fará sua doação.

Como recomendação e sugestão para próximos trabalhos relacionados ao assunto em questão, sugere-se que sejam feitas análises em fundações que atuam em outras áreas, a fim de verificar se a área de atuação interfere no modo em que prestam contas de suas informações contábeis à sociedade.

\section{REFERÊNCIAS}

BARBOZA, E. Gestão contábil e sistemas de informações aplicáveis às entidades sem fins lucrativos: aspectos legais, normativos $e$ deficiências. Disponível em: http://www.fundata.org.br/artigos.htm, Acesso em: 10/2005.

BRASIL. Lei n 10.406, de 10 de Janeiro de 2002. Novo Código Civil.

CONSELHO FEDERAL DE CONTABILIDADE. Resolução CFC 1.026/2005. Aprova a NBC T 10 - Dos Aspectos Contábeis Específicos em Entidades Diversas, o item: NBC T 10.16 - Entidades que recebem Subvenções, Contribuições, Auxílios e Doações e revogada pela NBC T 19.4; Disponível em: www.portaldecontabilidade.com.br/nbc/t1016.htm, acesso em 11/2005.

CONSELHO FEDERAL DE CONTABILIDADE. Resolução CFC 686/1990. Aprova a NBC T 3 - Conceito, Conteúdo, Estrutura e Nomenclatura das Demonstrações Contábeis. Disponível em: www.portaldecontabilidade.com.br/nbc/resolucoes.htm, Acesso em $11 / 2005$.

CONSELHO FEDERAL DE CONTABILIDADE. Resolução CFC 686/1990. Aprova a NBC T 6 - Da Divulgação das Demonstrações Contábeis. Disponível em: www.portaldecontabilidade.com.br/nbc/resolucoes.htm, Acesso em 11/2005.

CONSELHO FEDERAL DE CONTABILIDADE. Resolução CFC 837/1999. Aprova a NBC T 10 
Terceiro Setor: Aspectos relacionados à elaboração das demonstrações contábeis das fundações privadas mantenedoras de universidades do Estado de Santa Catarina José Alonso Borba, Rogéria Pereira, Eleonora Milano Falcão Vieira

- Dos Aspectos Contábeis Específicos em Entidades Diversas, o item: NBC T 10.4 Fundações. Disponível em: www.portaldecontabilidade.com.br/nbc/resolucoes.htm, Acesso em: 11/2005.

CONSELHO FEDERAL DE CONTABILIDADE. Resolução CFC 877/2000. Aprova a NBC T 10 - Dos Aspectos Contábeis Específicos em Entidades Diversas, o item: NBC T 10.19 - Entidades Sem Finalidades de Lucros. Alterada pelas Resoluções CFC 926/01 e 966/03 Disponível em: www.portaldecontabilidade.com.br/nbc/resolucoes.htm, Acesso em: 11/2005.

ESBEN, K.S. e LAFFIN, M. 2004. Terceiro setor e contabilidade: compilações de uma pesquisa. Revista Contemporânea de Contabilidade, Florianópolis, ano 01 (03):1128.

MACEDO, Sebastião Carlos Hanna de. Princípios e normas contábeis aplicáveis às entidades do terceiro setor: Aspectos legais, normativos e deficiências. Disponível em: http://www.fundata.org.br/artigos.htm, Acesso em: 09/2005.

PAES, E.S. 2003. Fundações e entidades de interesse social: aspectos jurídicos, administrativos, contábeis e tributários. 4ª ed. Brasília, Brasília Jurídica, 2003.

RESENDE, T.A. Terceiro setor, ONG's e institutos. Centro de Estudos de Fundações e Entidades de Interesse Social. Disponível em: http://www.fundata.org.br/artigos.htm, Acesso em: 09/2005.

SOUZA, C.J. O ministério público e o terceiro setor. Centro de Estudos de Fundações e Entidades de Interesse Social. Disponível em: http://www.fundata.org.br/artigos.htm, Acesso em: 09/2005.

UNIDAVI. Universidade do Vale do Itajaí. Disponível em: http://www.unidavi.edu.br, Acesso em: 09/ 2005.

UNISUL. Universidade do Sul de Santa Catarina. Disponível em: http://www.unisul.br, Acesso em: 01/2006. UNIVILLE.

Universidade de Joinville. Disponível em: http://www.univille.net, acesso em: 02/2006.

Data de Submissão: 27/08/2007

Data de Aceite: 31/08/2007 